\title{
Breve reseña sobre las causas de la instauración del neoliberalismo en México.
}

\section{Brief review on the causes of the establishment of neoliberalism in Mexico.}

\author{
Hugo José Regalado Jacobo \\ Facultad de Economía y Relaciones Internacionales. Universidad Autónoma de Baja California \\ (MÉXICO) \\ CE: hugo.regalado@uabc.edu.mx
}

DOI: $10.32870 /$ sincronia.axxiv.n77.24a20

Esta obra está bajo una Licencia Creative Commons Atribución-NoComercial 4.0 Internacional CC) $\mathrm{BY} \cdot \mathrm{NC}$

Recibido: $21 / 08 / 2019$

Revisado: $18 / 10 / 2019$

Aprobado: 05/11/2019

\section{RESUMEN}

La instauración del neoliberalismo en México forma parte de un proceso político-económico que tiene sus orígenes en los últimos años de la década de los setenta, entra en una etapa de transición en la década de los ochenta y se aplica durante los noventa; esta investigación profundiza en las causas que detonaron en el establecimiento del modelo neoliberal en México ¿Cómo? ¿Por qué? y ¿A quién benefició? Este fenómeno se aborda por medio de la metodología de análisis de coyuntura, la cual permite profundizar en los actores y factores más relevantes al interior de la estructura sistémica de cada etapa, este hecho ha podido corroborar que el establecimiento del neoliberalismo en México tiene su génesis en la recomendación de Organizaciones Internacionales que se legitimaron con la idea de cooperación para incluir nuevos actores a la toma de decisiones del Estado con la finalidad de evitar los excesos políticos anclados al modelo de Industrialización por Sustitución de Importaciones, no obstante, el resultado no fue el esperado, los beneficiarios directos de este proceso fueron políticos que se volvieron empresarios y empresarios que se volvieron políticos, una hibridación políticoempresarial. Este fenómeno permite replantear las causas y efectos en la configuración de estructuras 
de poder (élites) que se han beneficiado directamente del proceso de transición entre modelos económicos.

Palabras clave: Neoliberalismo. Modelo Económico. Coyuntura. Privatización. Inversión Extranjera Directa.

\section{ABSTRACT}

La instauración del neoliberalismo en México forma parte del proceso político-económico que tiene sus orígenes en los últimos años de la década de los setenta, entra en una etapa de transición en la década de los ochenta y se aplica durante la noventa; esta investigación profundiza en las causas que detonaron en el establecimiento del modelo neoliberal en México ¿Cómo? ¿Por qué? y ¿A quién benefició? Este fenómeno se aborda por medio de la metodología de análisis de coyuntura, el cual permite profundizar en los actores y factores más relevantes al interior de la estructura sistémica de cada etapa, este hecho ha corroborado el establecimiento del neoliberalismo en México tiene su génesis en la recomendación de Organizaciones Internacionales que se legitimó con la idea de cooperación para incluir nuevos actores a la toma de decisiones del Estado con la finalidad de evitar los excesos políticos anclados al modelo de Industrialización por Sustitución de Importaciones, sin importar, el resultado no fue el esperado, los beneficiarios directos de este proceso fueron políticos que se volvieron empresarios y empresarios que se volvieron políticos, una hibridación políticoempresarial. Este fenómeno permite reemplazar las causas y efectos en la configuración de estructuras de poder (élites) que se han beneficiado directamente del proceso de transición entre modelos económicos.

Keywords: Neoliberalism. Economic Model. Situation. Privatization. Foreign Direct Investment.

\section{Factores sistémicos}

La instauración del neoliberalismo en México forma parte de un proceso político-económico normativo paulatino que tiene sus orígenes en los últimos años de la década de los setenta, no obstante, diversos fueron los factores que detonaron su instauración. El concepto neoliberalismo ha 
cobrado gran relevancia durante los últimos años y ha sido utilizado en el argot político para hacer énfasis en los problemas económicos, políticos y sociales, originados por el cambio de modelo económico en México.

Este fenómeno se configura en dos momentos principales: el primero parte de lo internacional, se fundamenta en la recomendación de las Organizaciones Internacionales (O.I) ${ }^{1}$ de corte liberal para la instauración del proyecto como tendencia global; el segundo momento parte del contexto nacional que tiene su génesis en el proceso político-económico del último lustro de la década de los setenta, etapa anclada al estatismo nacionalista y al modelo (ISI) Industrialización de Sustitución de Importaciones.

Este marco coyuntural entrelaza diferentes factores exógenos y endógenos como la nacionalización de la banca, la caída de los precios del petróleo, el proceso de crisis económica de la década de los ochenta, la entrada de México al GATT y la instauración de las recomendaciones del Consenso de Washington, fenómenos que marcaron la pauta para la instauración del modelo neoliberal en México. La conjunción de elementos se unificó en el contexto de crisis económica, fenómeno que actuó como catalizador para el cambio de modelo económico que se fundamentó en privatización, liberalización y desregulación de empresas paraestatales, este hecho dio origen a la creación de una élite político-empresarial que se benefició durante el proceso de transición de un modelo a otro y utilizó la internacionalización como herramienta para la transnacionalización de empresas antes paraestatales.

\section{El génesis del modelo neoliberal}

Durante la década de los setenta se hicieron presentes asimetrías en el sistema político y económico ocasionadas por los excesos de la clase política de países que alcanzaron un crecimiento económico

\footnotetext{
${ }^{1}$ Al término de la segunda Guerra Mundial, se crearon una serie de Organizaciones Internacionales para la ayuda humanitaria, dentro de ellas las que se denominan Organizaciones Internacionales liberales como son: el Banco Mundial (BM), el Fondo Monetario Internacional (FMI) y el Acuerdo General sobre Aranceles Aduaneros y Comercio (GATT por sus siglas en inglés) que, sin embargo, convivieron con el Estado democrático de bienestar de bienestar que creó una red de protección social. (Borja, 2009).
} 
sostenido durante la etapa del modelo estabilizador; en esta etapa se propagó la idea del nuevo liberalismo encabezado por Margaret Thatcher (primer ministro del Reino Unido) Ronald Reagan (presidente de Estados Unidos de América) Paul Volcker (director de la reserva de Estados Unidos) y Deng Xiaoping de China) su discurso versó en la necesidad de un modelo económico-político internacional fundamentado en el libre mercado y la disminución del poder del Estado en la toma de decisiones, estas recomendaciones se crearon con la finalidad de regular los excesos de la alta burocracia en una primera instancia.

No obstante, las recomendaciones tuvieron efectos considerables en lo nacional; la transición de un modelo que estimuló estabilidad económica por treinta años, a otro que promovió la libertad económica tuvo repercusión en la esfera política, económica y social por la radicalidad con la que se efectuaron los cambios.

El crecimiento económico alcanzado durante el modelo ISI finalizó con la administración imprudencial del gasto público de la década de los setenta, fenómeno que llevó a la economía mexicana a una brecha creciente e insostenible a largo plazo, en donde se conjugó el ingreso, el gasto público, la estatización de negocios que nunca debieron haber quedado en manos del Estado como cabarets, fábricas textiles e inversiones azarosas (Calva, 1998) Estas acciones crearon elefantes blancos en áreas donde no era necesaria la mano del Estado, a este fenómeno se sumó el alza en los salarios de la burocracia, lo que ocasionó una amalgama de variables que drenaron de manera dramática las arcas del gobierno y lo condujo rápidamente a un déficit fiscal insostenible.

Para 1976 el gasto gubernamental como porcentaje del PIB representaba el 37.9\%, para 1982 representaba el $47.2 \%$, es decir, en menos de una década el gasto público se incrementó en casi el $10 \%$ del PIB. Para ese mismo período, los ingresos del gobierno eran de $28.8 \%$ y $30.3 \%$ del PIB, respectivamente, es decir, crecieron en menos de $2 \%$ del PIB, lo cual contrasta con el fuerte crecimiento en el gasto. El excesivo incremento en el gasto público se tradujo en un creciente déficit fiscal, para 1981 éste representó el 7.2\% del PIB. En ausencia de una reforma tributaria que permitiera al gobierno incrementar sus impuestos, el déficit fiscal fue financiado con deuda. En 1976 la deuda externa era del 32.6\% del PIB, para 1982 era del 43.1\%, 
es decir, el crecimiento en la deuda externa fue casi proporcional al crecimiento del gasto público, pese a que la deuda pública sólo creció en 5\% del PIB. (Velázquez y Vargas, 2014).

El problema del déficit fiscal pudo haberse solucionado con deuda en la medida de los ingresos derivados del petróleo; no obstante, la caída del precio del petróleo afecto directamente las tasas internacionales de interés, las cuales se incrementaron, agregando al proceso de crisis la fuga de capitales como factor que detono que el 20 de agosto de 1982, el Estado Mexicano declarara moratoria de pagos de la deuda externa.

A pesar de los problemas que derivaron en los procesos de crisis de los ochenta relacionados con los excesos gubernamentales, el crecimiento económico durante el modelo ISI hasta antes de la década de los setenta alcanzó los niveles más altos respecto a la tasa de crecimiento alcanzada durante toda la etapa Neoliberal. (Ver gráfica 1)

\section{Gráfica 1}

\section{Crecimiento económico durante el desarrollo estabilizador}

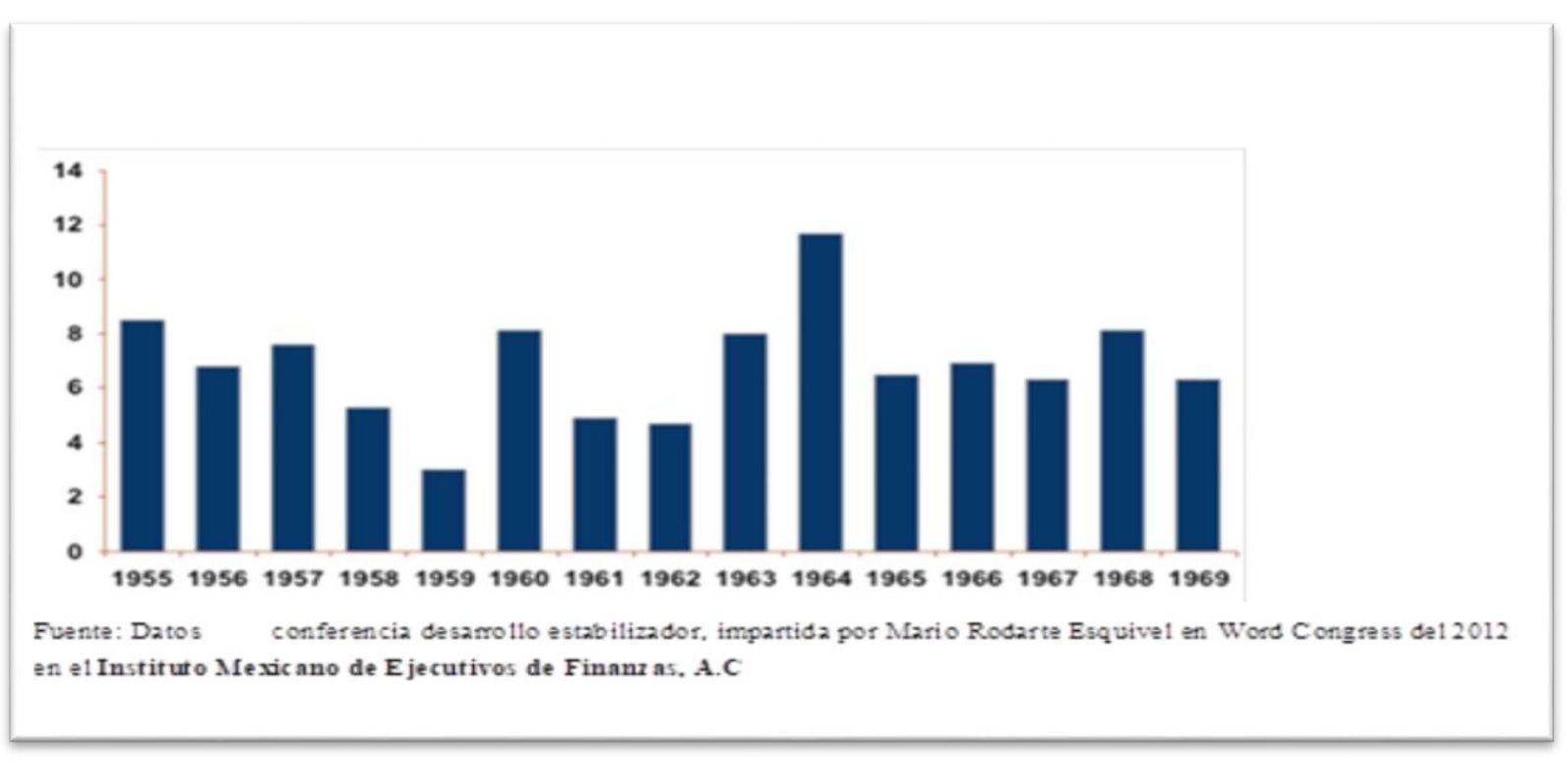

Fuente: Rodarte, 2012 
La contradicción entre el crecimiento del PIB de las décadas mencionadas, estimulado en gran parte por la exportación de petróleo se contravino con el incremento excesivo del gasto público, este fenómeno originó una crisis en el modelo económico, sin tener necesariamente un agotamiento que finiquitara su acción; en ese contexto, los datos muestran la viabilidad para corregir al modelo mediante mecanismos que restringieran el gasto público exportando más de lo que se importaba, este mecanismo pudo trasladar la economía nacional a un modelo mixto y dejar a la inversión privada con un porcentaje de participación de $40 \%$ y al gobierno un $60 \%$ sin tener que recurrir de tajo a la privatización total. A pesar de las variaciones del PIB durante el ISI, el crecimiento económico de esta etapa es considerablemente mayor que lo alcanzado durante el modelo Neoliberal. (Ver gráfica 2)

Grafica 2.

Producción Nacional (PIB) 1960-2012

\section{Crecimiento del PIB (\% anual)}

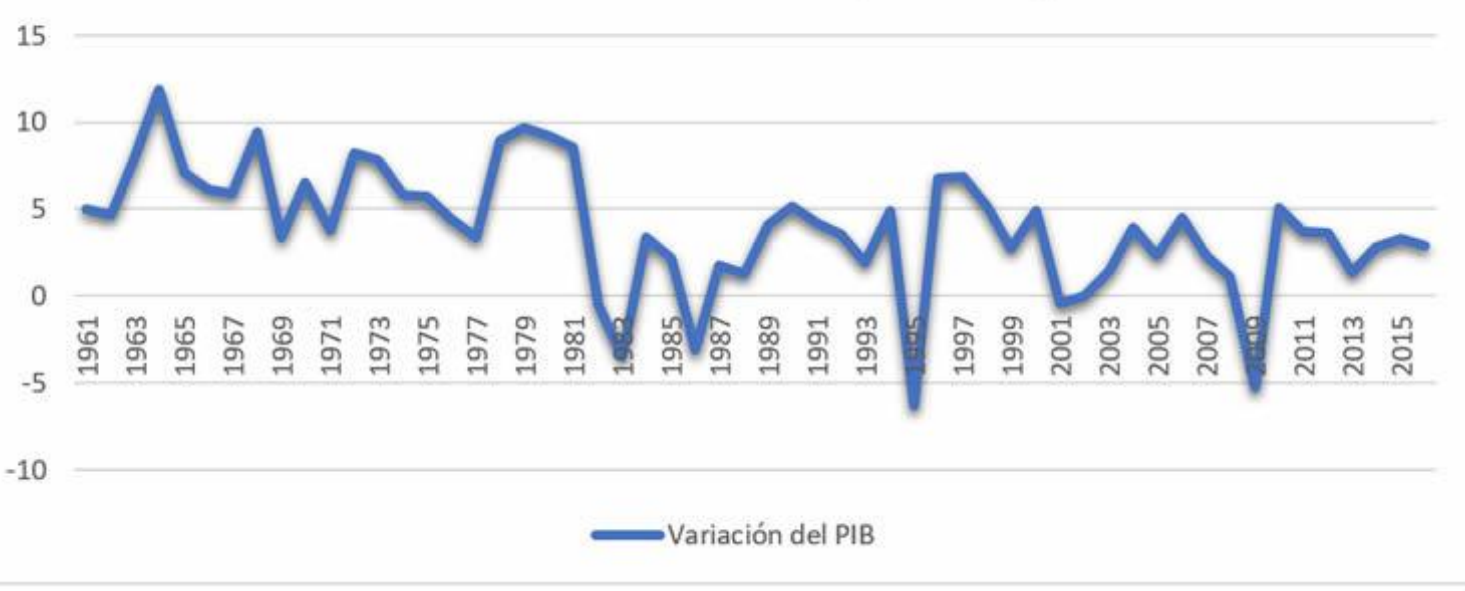

Fuente: Elaboración propia con datos de World Bank Group, 2016.

https://datos.bancomundial.org/indicador/NY.GDP.MKTP.KD.ZG?locations=MX 
Los factores exógenos que estimularon las múltiples transformaciones en la economía nacional ${ }^{2}$ se convirtieron en parteaguas fundamentales que permiten entender los procesos coyunturales así también la reestructuración del capital internacional, este contexto tuvo un efecto considerable en la política económica la cual se orientó a corregir los desequilibrios (Velázquez y Vargas, 2014) internos en las áreas responsables mediante recortes al gasto público, aumento en los ingresos mediante impuestos y servicios públicos y la venta de empresas paraestatales.

Las presiones de las nuevas relaciones comerciales a nivel internacional y la adhesión de México al Acuerdo General sobre Aranceles y Comercio (GATT por sus siglas en ingles) en 1984 plantearon la urgente necesidad de alcanzar en el corto plazo niveles de eficiencia internacional. (Ver gráfica 3). (Basave, 2000, p. 254).

\section{Grafica 3}

Variación del PIB Per Capital 1951-2015

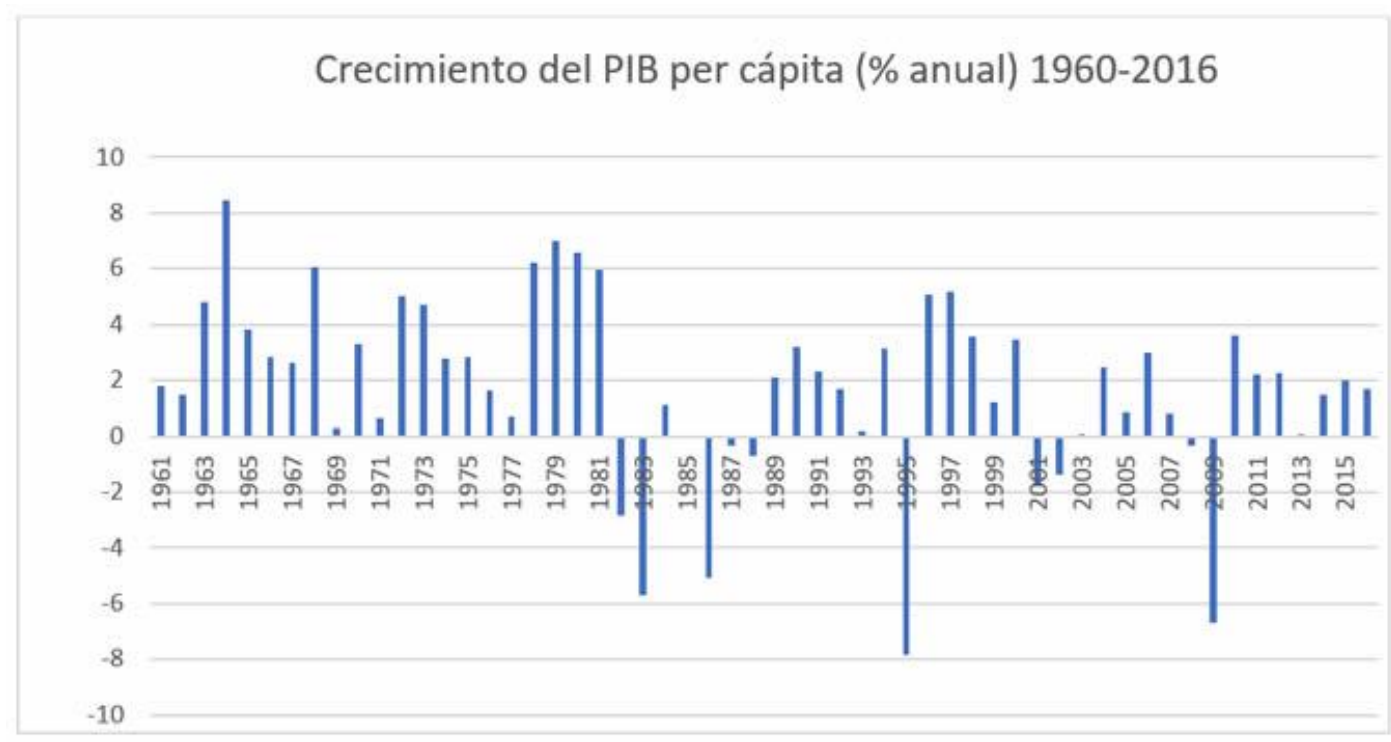

Fuente: Elaboración propia con datos de World Bank Group, 2016.

https://datos.bancomundial.org/indicator/NY.GDP.PCAP.KD.ZG?locations=MX

\footnotetext{
${ }^{2}$ El agotamiento del modelo vigente durante el periodo 1933-1980, conocido como industrialización mediante la sustitución de importaciones (ISI), promulgó las bases para emprender las reformas estructurales necesarias que permitiesen cambiar el rumbo económico del mundo. (ICE, 2004).
} 


\section{Transición entre modelos económicos}

Uno de los efectos del proceso de transición entre proyectos económicos fue la aparición de nuevosviejos actores en el proceso de construcción de reformas para la liberalización de la economía nacional que en fue la fusión entre empresarios y la élite política de esa década también llamada (Tecnocracia):

La política económica de liberalización, privatización y desregulación tuvo como meta crear condiciones para la elaboración de políticas institucionales adecuadas para la transformación en la correlación de fuerzas de las clases, tanto nacional como internacional; he aquí la condición para la reorganización técnica de la producción capitalista. (Hirsh, 1996, p. 90).

Sin conocer los resultados que el modelo tendría en los países, el discurso promovido por las cúpulas de poder fue: "El salto a la democracia mediante la transición política" En ese tenor, la globalización actuó como catalizador de la economía mundial la cual llevo consigo la predisposición de liberalizar los mercados. "La internacionalización de la producción bajo el monopolio de las empresas transnacionales favorecidas por la privatización; el comercio global y el manejo de los mercados por formaciones de alianzas estratégicas oligopólicas mundiales, a través de las fusiones y adquisiciones". (Pérez, 2013, p. 114).

El proceso de reestructuración sistémica ha permitido la observación de las etapas coyunturales más importantes que se ven reflejadas en la reconfiguración del capital internacional, fenómeno que tiene una perspectiva polisémica respecto a la aplicación y los resultados:

Los actuales monopolios u oligopolios privados surgen de una relación en la que el gobierno dio importantes concesiones a ciertos grupos empresariales, tanto en la época de economía cerrada, como en la época liberal; se dio una simbiosis entre intereses gubernamentales y privados que constituyó uno de los principales problemas al desarrollo en la época pasada y es un obstáculo importante en la actualidad. (Bizber, 2008, p. 3). 
A pesar de no tener en cuenta las repercusiones derivadas del cambio de modelo, este hecho fue un giro histórico para las economías como México que conjugaban hasta ese momento un fuerte proteccionismo estatal con un gran déficit resultado del mantenimiento de las paraestatales.

La adaptación del sistema de economía de mercado figuró como un mecanismo que en el discurso podría llevar a los países subdesarrollados a gozar de los beneficios de la autorregulación del mercado que controlaría la interacción de producción y comercio internacional. Con base en lo antes mencionado, la privatización y la desregulación como herramientas de política económica estimularon de manera gradual la eliminación de normas que regulaban las barreras comerciales.

La apertura comercial orientada hacia la exportación y competitividad de la economía, y la inversión extranjera directa como complemento a la inversión nacional, buscó en primera instancia contribuir a los objetivos de incrementar la eficiencia en los factores de producción e incentivar mayor inversión y crecimiento económico, así como un nivel de bienestar más alto de la población. (Rogozinski, 1997, p. 89).

En ese contexto, la adaptación de los puntos normativos del Consenso de Washington ${ }^{3}$ (que surgió en 1989 con la finalidad de establecer normas respecto de la política económica), se convirtieron en lineamientos que dieron la pauta para el derrumbamiento del sistema político económico anterior e implementar el modelo Neoliberal.

El Consenso de Washington debe mucho al triunfo del sistema neoliberal, pues le permitió vencer al antagonismo de propuestas de corte más intervencionistas. De esta manera, se inició un período más abierto, caracterizado por encontrar soluciones tan útiles como pragmáticas. (Casilda, 2005, p. 46).

Con la intención de orientar a los gobiernos de los países subdesarrollados y vincularlos directamente con las instituciones de gobernanza internacional de corte liberal: FMI, BM y OMC antes GATT, las

\footnotetext{
${ }^{3}$ Se le denomina Consenso de Washington a las medidas recomendadas por las OI, destinadas a la reestructuración del modelo económico implementadas hasta ese momento en países en desarrollo
} 
recomendaciones del CW estuvieron destinados a encontrar soluciones para ayudar a los países a afrontar la crisis de la deuda externa, fueron adaptadas por los gobiernos como un posible catalizador que serviría para impulsar a las economías de los países y alejarse de manera gradual de los procesos de crisis de los ochenta, sin embargo, las recomendaciones encaminadas a favorecer a la población en general terminaron por beneficiar a la élite político-empresarial ${ }^{4}$.

El primer momento coyuntural se comenzó a gestar desde los procesos de desregulación de empresas nacionales, que surgieron a durante el último lustro de los años setenta y principios de los ochenta, como resultado del conflicto entre Estado y empresarios en disputa por la nacionalización de la banca ${ }^{5}$, este fenómeno generó un entramado entre el grupo de asesores del presidente de la Madrid y la ola de privatizaciones a nivel nacional:

Simultáneamente el nuevo equipo del presidente Miguel de la Madrid mostraba una decidida intención de modificar el modelo de crecimiento económico hacia uno abierto y secundario-exportador en el cual la inversión externa y los grupos empresariales privados fueron los pivotes fundaménteles para su viabilidad. (Basave, 2000, pág. 256)

Este período de tiempo exterioriza la incógnita sobre ¿Quién o quiénes serían los más grandes beneficiados del proceso de privatización de empresas estatales? las respuestas no han sido claras, el proceso de transición de una economía proteccionista a la liberalización total de la misma ha sido paulatina respecto a los mercados (financiero y comercial); lo único palpable durante este proceso, fue la conformación de conglomerados empresariales nacionales en contubernio con empresas multinacionales, mismas que fueron apoyados por los grupos de poder político nacional: estos actores han sido los beneficiados del proceso de privatización mexicano y al mismo tiempo fueron los

\footnotetext{
${ }^{4}$ La instauración del modelo neoliberal corresponde a la inserción de los países subdesarrollados en una economía de mercado, la cual fungía como catalizador para la adaptación de los puntos más importantes del CW Como son: la privatización de empresas estatales y la desregulación de los mercados para lograr el crecimiento económico.

${ }^{5}$ Los últimos años del sexenio de Luis Echeverría Álvarez se vio marcado por el último esfuerzo por recuperar el nacionalismo económico uno de esos esfuerzos se convirtió en la nacionalización de la banca, fenómeno que distancio a los empresarios del gobierno federal, esta rebelión años más tarde dio como resultado la inserción de los empresarios más prominente a las filas del PAN y la pérdida del primer municipio en 1983 en Ensenada Baja California.
} 
gestores de la política que derivó en la negociación del Tratado del Libre Comercio de América del Norte (TLCAN) NAFTA por sus siglas en ingles.

Factores de carácter político fueron determinantes en 1988 cuando se firmó el primer Pacto de Solidaridad Económica (PSE) encabezados por el gobierno y los empresarios de los grupos oligopólicos de mayor dinamismo (industrias y casas de bolsa), a partir del cual los empresarios participaron activamente en el diseño de la nueva política económica del país y unos años más tarde en las negociaciones de la firma del Tratado de Libre Comercio de América del Norte (TLC). (Basave, 2000, p. 257).

\section{Actores y Factores durante el proceso}

En términos de política internacional, todo movimiento o coyuntura política requiere de sujetos o actores sociales, en este contexto, se observa la transición de las elites nacionales, las cuales utilizaron estrategias de diversificación para transnacionalizar empresas paraestatales adquiridas durante el proceso de privatización, este fenómeno se ha convertido en parte fundamental para la creación de grupos de poder fundados por empresarios y políticos de alto nivel.

La construcción de una élite político-empresarial encargada de administrar los sectores estratégicos privatizados más rentables del país fue organizada por el Estado que mediante diferentes mecanismos empodero a los nuevos actores en los sectores de reciente apertura como son el Bancario, Telecomunicaciones y de Minerales.

En los ochenta era necesario precisar dos propósitos fundamentales, en primer lugar, el Estado pretendía reforzar, preparar y proteger a las corporaciones privadas mexicanas, en particular las vinculadas con los sectores bancario, de telecomunicaciones, y de minerales con el propósito de que bajo la dirección de dicha oligarquía se fincara un sólido proceso que permitiera encarar la nueva concurrencia capitalista; y en segundo lugar, garantizar las mejores condiciones de inversión a las corporaciones multinacionales al amparo de la apertura comercial iniciada en los ochenta y reforzada por el Tratado de Libre Comercio al inicio de la década de los noventa. Si bien es cierto que el eje de las reformas tenía como propósito que la rearticulación del capitalismo mexicano estuviera dirigida 
por la oligarquía financiera nacional y la de telecomunicaciones, los resultados no fueron los esperados (Morera, 2002).

La conformación de grupos de poder durante lo que se denomina etapa de transición entre modelos económicos, es decir, entre los ochenta y noventa en donde se gestó la correlación entre la élite pública y privada con los patrones de conducta que los relacionan en función del poder, de esta manera, interactúa el empresario que apoya económicamente la carrera del político y cuando este alcance sitios claves en la esfera política, el político otorga al empresario concesiones que son función del Estado, este ejemplo se ve muy marcado con el proceso de privatización y las franquicias otorgadas con respecto a televisión, radio, telecomunicaciones, tierras de explotación ricas en minerales, infraestructura carretera, construcción, aerolíneas y prestación de servicios para empresas estatales como Pemex.

Los puntos de contacto entre el poder económico y la política formal e informal definen los estilos de negociación entre empresarios y políticos. La moneda de intercambio suele ser la corrupción, en todas sus formas; sobornos o cohechos, dependiendo de cuál de los dos actores, el empresario o el político, comience el intercambio (Ramirez, 2019).

La desincorporación paulatina dados en durante el sexenio de Miguel de la Madrid, alcanzaron su punto máximo en el sexenio de Carlos Salinas de Gortari presidente que buscó fortalecer el modelo neoliberal en su sexenio, las etapas precedidas por los actores mencionados se han visto marcados por favoritismo y clientelismo político, este hecho originó la corrupción sistémica actual y estimulo un empresariado dependiente de las concesiones estatales.

\section{Dialéctica ente empresarios y políticos}

Los grandes monopolios nacionales transnacionalizados se deben en gran manera a la concesión de infraestructura básica estatal que depende en su mayoría de la elaboración de políticas que legitiman el poderío empresarial. La falta de avances tecnológicos en la industria mexicana se encuentra anclada a la filosofía tradicional de un empresariado falto de innovación que depende del gobierno, ya sea federal, estatal o municipal. 
Los empresarios mexicanos se caracterizan por tener rasgos que marcan su actuar dentro de los procesos históricos políticos y sociales, que configuran su desarrollo con base en su bagaje ideológico; Antes de la década de los ochenta los empresarios vinculaban sus propuestas por medio de canales extraparlamentarios debido a la falta de representación en el partido único que no coadyubaba con el conservadurismo empresarial, se encontraba ideológicamente vinculado al nacionalismo político, no obstante, a pesar de las complicaciones estructurales, el poder empresarial mantuvo un lugar relevante en el sistema económico representado por dos grupos empresariales: el Grupo Monterrey y el Grupo del Centro cada uno conjuntaba actividades en el sector industrial y financiero respectivamente.

La delgada línea de separación entre empresarios y políticos culminó en 1982, con la nacionalización y privatización de la banca, este proceso rompió los acuerdos establecidos por el Estado en primera instancia, mismos que enmarcaban la designación del sector financiero a un determinado grupo empresarial. No obstante, la ruptura privatizadora dio pie a la incursión del empresariado dentro de la política nacional para formar parte de un proceso de reconfiguración Político-Empresarial al interior del Partido Acción Nacional (PAN), formado originalmente por oligarcas, comerciantes y empresarios mexicanos. A diferencia de muchos países de América latina, en México los empresarios han estado fuertemente organizados y tenían un contacto continuo con el gobierno (Schneider, 2002).

La coyuntura histórica de este periodo se caracterizó por redefinir la relación tradicional entre Estado y empresariado, redimensionando de esta manera la estructuración de un nuevo actor internacional como ente predominante en las relaciones de poder y la toma de decisiones en el plano político y posteriormente en el marco de la crisis, este hecho, aporto nuevas formas de análisis para el estudio de ciclos que determinan la unificación de la figura política con la élite empresarial.

Ilan Bizberg en el artículo titulado: "Alianza de Empresarios" (2008) de la CEPAL expresa como punto de partida al anterior proceso, que el final de los años setenta ${ }^{6}$ como génesis temporal, se

\footnotetext{
${ }^{6}$ La culminación del proceso de articulación del empresariado se encuentra determinado por el cambio de gobierno de la Presidencia de la República presidida por Adolfo López Mateos, el principal acto que define este hecho es la creación del
} 
convertiría en testigo fiel del desarrollo de la clase empresarial en México que había prosperado amparado por la protección y el favoritismo gubernamental hacia los más poderosos.

El Consejo Coordinador Empresarial surgió como una asociación civil, que se distinguió desde un principio de las organizaciones obligatorias como la Confederación Nacional de Cámaras industriales (CONCAMIN), la Cámara Nacional de la Industria de la Transformación (CANACINTRA) y la Confederación Nacional de Cámaras de Comercio (CONCANACO) que fueron creadas por el gobierno con el objetivo de tener interlocutores empresariales unificados. (Bizber, 2008).

De acuerdo a Valdez Ugalde, el CMHN se fue configurando como la principal organización del empresariado nacional, por encima de las organizaciones corporativas y desde su creación lleva a cabo reuniones periódicas con el presidente del país y con los principales funcionarios que definen la política económica. (Valdés, 1997, p. 163).

\section{La rebelión de los empresarios}

El peso del núcleo empresarial en la política mexicana llevo a reconsiderar el poder político a favor de los empresarios, este fenómeno brindo legitimidad al empresariado por medio de un movimiento político proempresarial en donde convocaron a marchas constantes para pedir la privatización de la banca recién nacionalizada, estos movimientos fueron encabezadas por CONCAMIN, CANACINTRA, CONCANACO y CCE; estas instituciones se fortalecieron económicamente del movimiento políticoempresarial, gestándose de esta manera una nueva coyuntura política, marcada por la cooperación entre la élite empresarial mexicana y la élite empresarial norteamericana.

A finales de octubre, Henry Kissinger y Nelson Rockefeller visitan a los dos presidentes, (el saliente y el electo) y el primero declara al partir, que Miguel de la Madrid tenía claro que México necesitaba de una mayor fortaleza de la iniciativa privada. En tanto, en la revista New York Times

Consejo Mexicano de Hombres de Negocios (CMHN), que reunía exclusivamente a los principales empresarios del país. (Ortiz, 2000). 
aparece un documento firmado por 35 diputados en el que se condena la nacionalización y el control de cambios (Millán, 1988, p. 76).

El nuevo gobierno propuso una reconversión del sector productivo del país para lograr un desarrollo anclado a la libertad económica. En este marco, en 1985 México aceptó solicitar su ingreso al GATT (Acuerdo General sobre Aranceles y Comercio) e iniciara una paulatina apertura económica, misma que tuvo grandes costos para una industria mexicana que gozaba de una alta protección arancelaria y administrativa, tal y como Estados Unidos había sugerido sin mucho éxito poco antes de la crisis de 1982.

Las relaciones políticas y económicas entre México y Estados Unidos fueron determinadas por el dinamismo del sistema internacional que se adecuo a las necesidades económicas de Estados Unidos, para lo cual, la negociación de la desregularización de la banca era solo el principio de una serie de privatizaciones de empresas estatales:

Aunque los procesos de fusión y adquisiciones de empresas son muy anteriores a la década de los ochenta, es precisamente con la nacionalización de la banca que comienza un importante proceso de restructuración del sector financiero. Tal proceso se podría dividir en tres etapas. La primera incluye la nacionalización de la banca en 1982 y se prolonga hasta 1989; la segunda, que va de 1990 a 1995, compromete la reprivatización de la banca comercial nacionalizada y la crisis del sistema financiero, y la última, de 1995 a nuestros días cuando los grupos financieros nacionales se consolidan en primer momento y posteriormente sobreviene la adquisición de la gran mayoría de la banca comercial y las principales instituciones de seguros de la banca extranjera (Vidal, 2008, p. 349). El Fondo Monetario Internacional a través de las recomendaciones destinadas a eficientizar la economía mexicana propuso "la privatización de empresas estatales que resultaban ineficientes" este efecto resultó tener un carácter estratégico para la oligarquía nacional, es el caso de las telecomunicaciones, mineras, cementeras, aerolíneas, líneas de ferrocarril, autopistas, bancos y canales de televisión : TELMEX (Teléfonos de México) sería adquirida por el grupo CARSO de Carlos Slim Helú; las Mineras y Siderúrgicas absorbidas por PEÑOLES perteneciente al conglomerado Grupo Bal de Alberto Bailleres, Grupo México de German Larrea mineras, líneas de ferrocarril, empresas 
vinculadas a la extracción de petróleo, Banamex de Roberto Hernández, Roberto González propietario de Banorte, Ricardo Salinas de Imevisión y Pedro Aspe Armella propietario de Aeroméxico. Durante el proceso de privatización, los empresarios se vieron apoyados en todo momento por la nueva clase política (tecnocracia) e instituciones de gobernanza internacional de corte neoliberal.

Un factor que contribuyó de manera paulatina el incremento de las adquisiciones estatales por parte de funcionarios públicos fue la rapidez y la falta de revisión en los mecanismos establecidos para la liquidación de las empresas, esto fenómeno se dio como consecuencia indirecta del proceso de privatización.

México se convirtió en receptor de Inversión Extranjera Directa fenómeno que provocó un efecto adverso a lo esperado el retroceso en la economía:

A pesar de que el TLCAN dio frutos al triplicarse las exportaciones de México a los EEUU y al convertirse el país en el principal destino de Inversión Extranjera Directa de América Latina en sus primeros 10 años, la política hacia los grandes grupos no ha dado los frutos esperados de crecimiento y de competitividad del resto de la economía. En efecto, según una reciente encuesta del Centro de Estudios del Sector Privado (CEESP), los empresarios afirman que los dos principales obstáculos para el desarrollo empresarial son los monopolios públicos (83\% de frecuencia) y privados (84\% frecuencia). (Centro de Estudios del Sector Privado (CEESP, 2005).

El anuncio de la suspensión de las reuniones del Consejo Mexicano de Hombres de Negocios (CMHN) con el Presidente de la República coincidió con la firma de la Carta de Intención entre México y Fondo Monetario Internacional, otorgándole al país un crédito por 3,840 millones de dólares distribuidos en tres años por lo que el Estado se vio obligado a revisar las tarifas del sector público y a controlar su déficit presupuestal; El recurrir al FMI fue demanda de todo el empresariado después de la nacionalización. (Millán, 1988, p. 176).

Con la finalidad de beneficiar al empresariado, el Estado otorgo contratos preferentes con dependencias del gobierno y utilizó a favor de los empresarios las leyes, tarifas, aranceles y 
financiamientos para dar mayor participación a determinados grupos empresariales que mantenían mayor relación con la clase política (compadrazgo) a fin de mantener una relación recíproca.

Estos mecanismos han sido importantes para la consolidación de los oligopolios actuales. El cargo público permitió a muchos políticos iniciar su carrera empresarial para después constituir una nueva forma de acumular riquezas personales:

La acumulación de riquezas personales de empresarios a costa del presupuesto público no es un fenómeno nuevo, este fenómeno data los primeros gobiernos revolucionarios y se acentúa durante el gobierno de Miguel Alemán cuando se acumularon grandes fortunas y se consolidaron importantes empresas en las que participaban algunos ex funcionarios. (Puga, 1993, p. 66).

Las negociaciones dadas bajo las coyunturas que correspondes a finales de los setenta, ochenta y noventa pertenecen a una serie de negociaciones entre empresarios y Estado, cada uno representado por facciones de poder. En el caso del Estado por funcionarios de alto nivel, por otra parte, el sector privado se encontraba representado por organizaciones empresariales como CONCAMIN, CONCANACO, CCE, COPARMEX.

La conjunción entre Empresarios y Políticos originó un proceso paulatino de configuración sistemática siendo hasta nuestros días uno de los momentos más importantes para entender el sistema político mexicano en correlación con la conformación de una élite que tiene características híbridas y cohabitan espacios que van entre lo público y lo privado, este hecho reconstruye una alternativa sociopolítica que permite estudiar a profundidad la configuración de una élite políticaempresarial inmiscuida en la toma de decisiones en el Estado.

\section{Neoliberalismo sistémico (Procesos de privatización, sectores y empresas)}

La privatización además de ser la venta de empresas del Estado al sector privado o elites empresariales se considera como una estrategia de la globalización de los mercados, en la que 
concurre la concentración económica y el reparto de mercados entre pequeños grupos de poder considerando una economía mundial con bloques y regiones.

El proceso de privatizaciones que dieron lugar el giro en la política económica interna inicio un nuevo ciclo de centralización de capital en el cual algunos de los grupos privados nacionales se diversificaron y otros lograron una mayor integración como parte de su reestructuración organizativa. (Basave, 2000, p. 88).

En el segundo punto de esta investigación estudia las coyunturas más relevantes como parte del antecedente histórico lo que permite conocer los momentos claves de la desregulación de empresas estatales y los ciclos en donde se conforma una élite con rasgos políticos y empresariales encargados de la negociación de la primera oleada de privatizaciones.

En este contexto, Horacio Boneo (1985) ha identificado tres tipos de privatización en este proceso:

a) La "privatización de gerencia", en el sentido de lograr un adecuado balance entre el componente "público" y el "empresarial" de una firma estatal, que en muchos casos parece estar sesgado hacia el primer componente.

b) "Privatización periférica", es decir, la venta de ciertas partes de la empresa, manteniendo el núcleo productivo bajo la propiedad estatal.

c) La privatización por medio de acuerdos y convenios con socios provenientes del sector privado, tanto nacionales como transnacionales" (p. 117).

Estas alternativas son mecanismos de reconfiguración en el sentido de creación de estrategias normativas con el propósito de eliminar paulatinamente el "poder del Estado" en empresas estatales, hecho que generó ganancias en la lógica del modelo Neoliberal para evitar las fugas de capital que el modelo proteccionista mantenía en torno a estas empresas como producto de la inestabilidad financiera. 
Durante el gobierno de Carlos Salinas de Gortari en el sistema financiero y en particular la banca, propició la integración de grupos o consorcios en manos del capital del país. Por ejemplo, las privatizaciones de empresas públicas realizadas durante el gobierno de Salinas de Gortari consideraban las modificaciones legales y el proceso mismo de venta de los activos, como medios para permitir que las nuevas firmas fueran adquiridas y controladas por el país. (Vidal, 2008).

La estrategia orientada a reformar la política económica en América Latina se desarrolló en centros de investigación patrocinados por el Banco Mundial, basando su interpretación en la teoría neoclásica del equilibrio general de competencia perfecta, la antítesis de la teoría de Joseph Stigltz que demostró que la información es imperfecta, por lo tanto, todo modelo económico debe de ser aplicado de manera distinta en cada uno de los países o regiones por falta de información.

La carencia de información y claridad en las negociaciones respecto a la venta de empresas estatales ha sido un elemento recurrente:

El proceso de privatización no sólo dio preferencia a ciertos individuos, sino que en muchos casos se llevó a cabo a partir de decisiones que reflejan acuerdos informales y poco transparentes entre el vendedor y el adquirente: como fue el caso de Aeroméxico o de la venta de la mina Cananea al Grupo México. (Valdés, 1997, p. 237).

El proceso de apertura económica y de desregulación de sectores estratégicos como el bancario y de telecomunicaciones, en correlación con las exigencias en condiciones de competencia, implicó que a finales de los noventa y principios del presente siglo, empresarios y políticos mexicanos de la mano de capital extranjero adquirieran un importante número de empresas a bajo costo antes propiedad del Estado; los verdaderos beneficiarios de esta política privatizadora fueron los dueños de los grupos económicos de propiedad familiar (Hogenboom, 2004, p. 207):

Los empresarios ocupan los principales puestos de representación de las organizaciones más influyentes del sector privado: el Consejo Mexicano de Hombres de Negocios, la Asociación Mexicana de Banqueros, la Asociación Mexicana de Instituciones de Seguros, que a inicios de los noventa sumaban apenas 121 personas y que controlaban los hilos de la representación y el poder de negociación del sector privado. (Valdés, 1997, p. 232). 
Las relaciones entre miembros de los Consejos empresariales mexicanos y el gobierno quedo expuesta en la campaña presidencial de Salinas, en donde la élite político-empresarial participó de manera activa para formar parte del grupo de asesores durante su mandato; después de dos años se ventilo en el segundo informe de gobierno que los mayores compradores de las empresas privatizadas fueron las familias de abolengo en correlación con miembros de los consejos empresariales.

En México se matizan empresas del Estado puestas a disposición de las oligarquías mexicanas, entre estas empresas destacan Aeroméxico, Mexicana de Aviación, Compañía Minera de Cananea, SIDERMEX, Teléfonos de México; también se vendieron los 18 bancos, producto de la nacionalización de 1988, que representó un monto global de 36 billones de pesos. (Salinas, 1990).

\section{El caso TELMEX}

El ciclo de privatización empató en etapa entre el sector de telecomunicaciones y el sector bancario, el primero se dio entre 1994 y 1998, estos 4 años aluden también a la privatización de Teléfonos de México que se ratifica años después entre 2000 y 2005 derivados de los cambios en la ley de telecomunicaciones (años que corresponden a la extinción del sindicato de electricistas SME)

El proceso de privatización que tiene su génesis en los años ochenta, tuvo un dinamismo importante entre 1988 y 1993 en ese lapso se remataron las empresas estatales más importantes así también los bancos, en el periodo que va de 1990 a 1992, este fue el momento clave del primer periodo de desregulación que corresponde a la privatización de Teléfonos de México (TELMEX).

El control de la compañía quedo en manos de Carlos Slim quien fusionó CARSO con SBC Comunications de Estados Unidos y France Telecom. Este hecho permite observar el papel de las organizaciones empresariales en la simbiosis entre políticos y empresarios. En ese contexto, el BM elaboró un informe en el 2007 sobre el proceso privatizador llevado a cabo durante el gobierno de Salinas. 
El proceso de privatización del sexenio de Salinas de Gortari involucró a algunas de las empresas más importantes del país, que aún conservaba el gobierno. Entre 1988 y 1992 se privatizaron, entre otras, Bancomer, Banamex, Comermex, Banca Serfín (así como los demás bancos), Teléfonos de México, Mexicana de Cobre, Compañía Minera Autlán, Fertilizantes Mexicanos, la Siderúrgica Lázaro Cárdenas, Altos Hornos de México, Aeronaves de México, Mexicana de Aviación, y otras. (Bank, 2007, p. 49).

De esta manera el Estado mexicano redujo su injerencia en la economía desde la presidencia de Miguel la Madrid, es decir, se dio un achicamiento del Estado; una de las primeras acciones se direccionó en retirar los subsidios de la industria y la agricultura nacional, este proceso sería acompañado por una fuerte concentración de capital.

La desregulación y las privatizaciones han permitido la creación de grupos financieros y empresariales si nosotros en México no tuviéramos grandes grupos, quedaríamos fuera de los mercados mundiales promovemos la formación de grandes grupos empresariales y su integración a cadenas productivas que estimulen la creación de más empleo (Valdés, 1997, p. 238).

Las políticas privatizadoras propiciaron la concentración del poder político y económico eliminando cualquier competencia en el ramo:

Esta política permitió que algunas de las grandes empresas nacionales, concentraran aún más su sector, al grado de que en 1991 Vitro, Alfa, Cifra, Cemex, Bimbo, Minera México e industrias Peñoles generaban el 56\% de las ventas, movilizaban el $61 \%$ de los activos totales y aportaban el 53\% del empleo de los 119 principales grupos mexicanos. (Hogenboom, 2004, p. 21).

El procesos de privatización en México obedece a dinámicas en dónde las fusiones y adquisiciones de empresas estatales se convirtieron en herramientas utilizadas por el Estado para la inserción del modelo neoliberal fenómeno que beneficio a los grupos empresariales nacionales apoyados en 
correlación con la tecnocracia que crearon instrumentos en conjunto para su internacionalización y posteriormente su posprivatización, legitimando la acción con el objetivo de obtener mayor participación de Inversión Extranjera Directa (IED) mexicana en el mundo, con la finalidad de elevar los ingresos nacionales, la creación de monopolios nacionales como es el caso de TELMEX, Grupo México y Peñoles estos grupos enmarcan los procesos más evidentes en relación a la creación de mayores ganancias de en los diferentes sectores del mercado.

La creación de nuevos monopolios empresariales quedaron en manos de actores públicos como el caso de Mexicana de aviación y Aeroméxico que fueron absorbidos por actores como Pedro Aspe Armella mentor político de la actual tecnocracia mexicana, estas dos aerolíneas mantuvieron un duopolio por algún tiempo, lo que significó altos precios en el transporte aéreo al interior del país.

\section{Conclusión}

Las causas de la instauración del neoliberalismo en México son multifactoriales, se correlacionan en el proceso histórico a través de coyunturas en dos rubros principales nacional e internacional; la primera se da en torno a factores exógenos en donde las actores y Organizaciones Internacionales jugaron un papel fundamental para la recomendación del programa neoliberal; la segunda, conglomera factores endógenos que agrupan múltiples fenómenos nacionales que propiciaron el cambio de modelo económico.

Este fenómeno representa un ejemplo claro respecto al efecto de las recomendaciones externas para la adaptación del proyecto neoconservador para países en vías de desarrollo. En México este hecho tuvo su génesis durante el mandato de Luis Echeverría, en el episodio conocido como la nacionalización de la banca. El efecto de esta etapa ocasionó la rebelión empresarial que cohesiono al empresariado nacional que estuvo representado por cámaras de comercio.

Durante esta coyuntura, la movilización del empresariado de la década de los ochenta fue capaz de presionar al Estado mexicano en correlación con la intervención del empresariado norteamericano, proceso que permitió negociar intereses de grupo, vinculados al sector bancario 
como primer momento para después beneficiarse de una serie de privatizaciones paulatinas, este fenómeno estuvo anclado al cambio de modelo económico.

En suma, la instauración del modelo neoliberal relacionó de manera sistémica la privatización de paraestatales con la conformación de una élite hibrida lo que dejó abierto el debate en torno al modelo económico que estimuló la acumulación económica en unas cuantas manos.

El presente permite observar factores, acciones y actores que se correlacionan de manera sistémica en una red de actores político-empresariales beneficiados por las reformas y el proceso de privatización, fenómeno que ha dejado una separación abismal entre ricos y pobres.

El estudio de esta investigación fue realizado en dos líneas paralelas al proceso de instauración del neoliberalismo lo que arroja resultados importantes para analizar la pertinencia en la elaboración de un modelo económico mixto, que tenga en cuenta los excesos derivados del modelo ISI y por otra parte el proceso de crisis constante ocasionado por la desigualdad sistémica del modelo neoliberal; en ese contexto se rescatan los aciertos más importantes de ambos modelos con la finalidad de establecer un modelo hibrido que coadyuve políticas sociales con un dinamismo económico, fenómeno que ocasionaría un equilibrio con efectos positivos y favorables para la población.

\section{Referencias:}

Bank, W. (2007). Democratic Governance in Mexico: beyond State capture and social polarization. México: World Bank.

Basave, J. (2000). Empresas mexicanas ante la globalización (Primera Edición ed.). Distrito Federal, México: UNAM.

Bizberg, I. (2008). Alianzas público-privadas, estrategias para el desarrollo exportador y la innovación: el caso de México. Recuperado de : http://proyecciones.colmex.mx/PDFs/Prof\%20Bizberg/alianzas\%20p\%C3\%BAblico\%20privadas. pdf

Boneo, H. (1985). Privatización del dicho al hecho. Argentina: Cronista comercial. Borja, A. (2009). Interdependencia, cooperación y globalismo. México: CIDE. 
Casilda, R. (2005). América Latina: Del Consenso de Washington a la Agenda del Desarrollo de Barcelona. [Documento de trabajo]. España: Real Instituto Elcano de Estudios Internacionales y Estratégicos. Recuperado de https://docplayer.es/1195947-America-latina-del-consenso-dewashington-a-la-agenda-del-desarrollo-de-barcelona.html

Centro de Estudios del Sector Privado (2005). Encuesta: Gobernabilidad y desarrollo empresarial. México: Consejo Coordinador empresarial.

Hirsh, J. (1996). Globalización, Capital y Estado. México: UAM-XOCHIMILCO.

Hogenboom, B. (2004). “Economic concentration and conglomerates in Mexico". Journal of developing Societies, 20(250).

Millán, R. (1988). Los empresarios ante el Estado y la Sociedad. México. México: Siglo XXI.

Morera, C. (2002). La nueva corporación Transnacional en México y la Globalización. [Archivo de audio] México: UNAM. Recuperado de https://datosabiertos.unam.mx/IIEc:RU-UNAM:684132

Ortiz, A. (2000). EL CONSEJO MEXICANO DE HOMBRES DE NEGOCIOS. Ciudad de México: UNAM.

Recuperado de http://lasa.international.pitt.edu/Lasa2000/OrtizRivera.PDF.

Pérez, R. (2013). Privatizaciones, fusiones y adquisiciones: las grandes empresas en México. Espacios Públicos. 16(37). pp. 113-140.

Puga, C. (1993). México: Empresarios y poder. México: Miguel Ángel Porrúa.

Rodarte, M. (2012). Crecimiento económico durante el desarrollo estabilizador. Word Congress. México: Instituto Mexicano de Ejecutivos de Finanzas A.C.

Rogozinski, J. (1997). La privatización en México "Razones e Impactos". México: Trilllas.

Salinas, C. (1990). Segundo informe de gobierno. México: Gobierno de la República.

Schneider, R. (2002). “¿Why is Mexican Business so organized?” Latin American Research Review. 37(1). pp. 77-118. Recuperado de https://www.jstor.org/stable/2692105

Valdés, F. (1997). Autonomía y Legitimidad. Los empresarios, la política y el estado en México. México: Siglo XXI-UNAM. 
Velázquez, D. y Vargas, J.R. (2014). El modelo Neoliberal y su efecto en el crecimiento económico: El caso de la economía mexicana. Boletín Científico de las ciencias económico administrativas del ICEA. 3(5) DOI: https://doi.org/10.29057/icea.v3i5.112

Vidal, G. (2008). “Empresas transnacionales, inversión extranjera directa y financiamiento de la inversión la inversión en México. En Guillen, A. e Ivanova, A. Globalizaciòn y regionalismo: economía y sustentabilidad. México: Miguel Ángel Porrúa.

World Bank Group. (2016). Crecimiento del PIB per cápita (\% anual) - Mexico. World Bank Group. Recuperado de: https://www.worldbank.org/. 